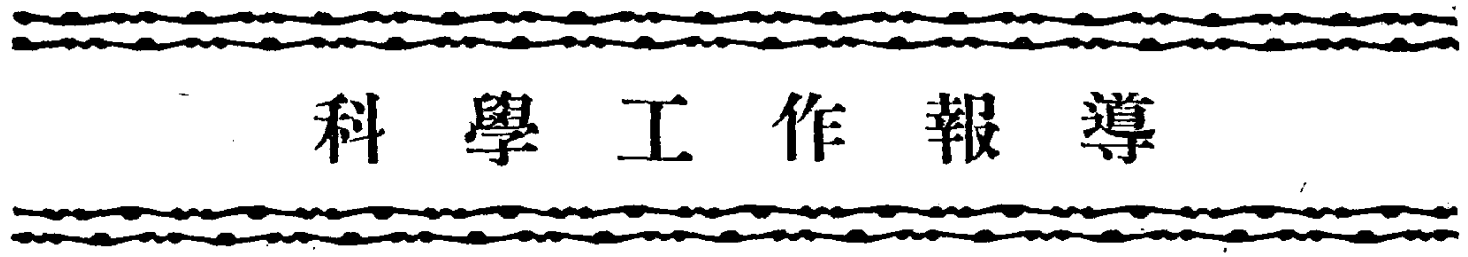

\title{
人工單性雷的大批美商及其繁殖
}

張果葉峰

1

（中國科學院宽盘生物研究的）

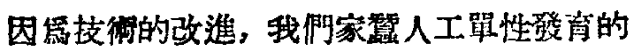
成精亦逐年提高。

在過去三年裹 (1949-1951)，我門一共得

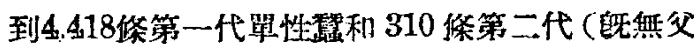

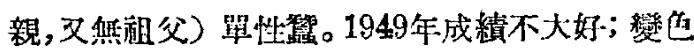

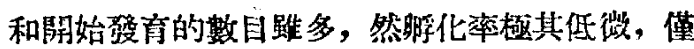
$0.055 \%$; 只有 8 集小箭，而且都是政性的。1950年

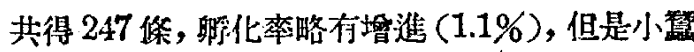

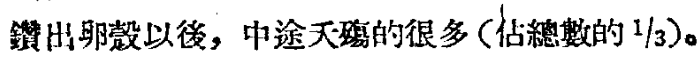

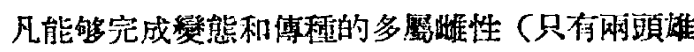

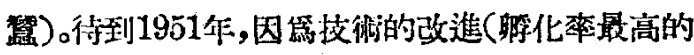
能達 $55 \%$ )，一共得到 4,163 焂小琵。至于將出而

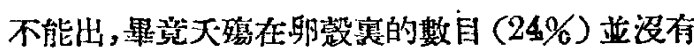
統計進去。闰年秋天,卯育了一批(310焂)第二代 單性篦，牠們也很好地竟其發育的荃程。

關于1949-1950年所養育的單性琵已經在本

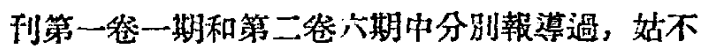

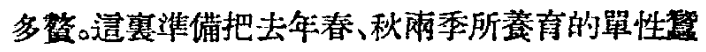
的工作絬果，擇要報告一下。

\section{一 第一代單性生殖的幼䖽的生舆情况}

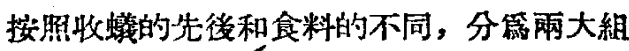
養育。第一大組肉分公僻小組,收䗷日期,從 4 月 20 日起至28日止; 共有 3,061 條(見圖 1 ), 全路吃

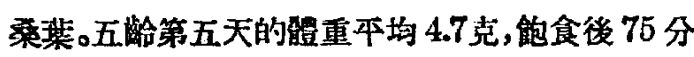

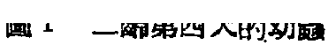

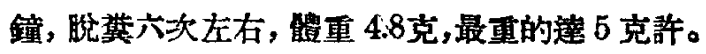
5 月31日開始結藏。

第二大組內分四個小組。收蛴日期：4月28 日一 5 月 1 日,共 1,100 焂; 三齢前,吃蒲公英"，

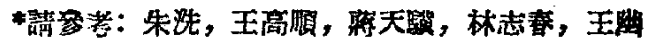

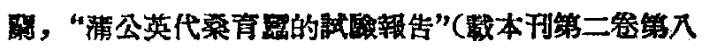
期, 1951)。 
葸亘勧等;三路以後,改食桑渠。

在這 4,163 佟單性等中, 早期死亡(死于䌿眠

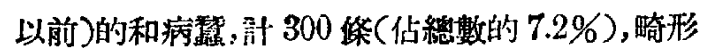

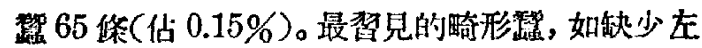

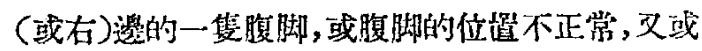
氣孔的數目和位造反常; 還有些瑟，他們背部的斑

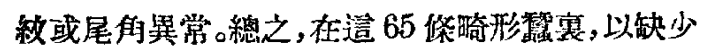
第一對腹肢某涭的一隻秀最多。餘下來的 3,863 㷛,在外形方面燋不出甚碳㙷著的畸形來。他們都

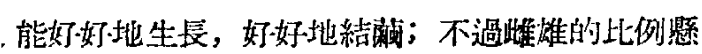
殊; 就中只有兩佟是谁性子沓( 佔 $0.05 \%$ )。

\section{二 關於絲品筫的初步檢查}

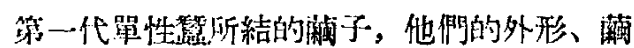

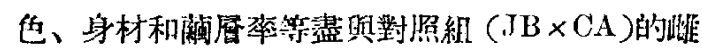

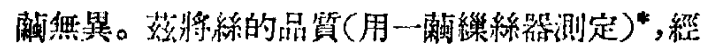
過初步检查的結果,列表祛朋之。

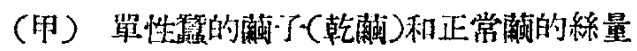
及絲舆之此較表:

\begin{tabular}{|c|c|c|c|c|c|}
\hline 類 別 & 回稘 & 切断 & (䋃辰) & 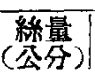 & $\begin{array}{l}\text { 織度 } \\
(10 .) 4\end{array}$ \\
\hline 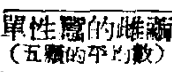 & 85 & 1.25 次 & 933.33 & 0.3055 & 3.2361 \\
\hline $\begin{array}{l}\text { 對 } \\
(\mathrm{JB} \times \mathrm{CA} \text { 組 }\end{array}$ & 872.0 & 次 & 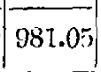 & 326 & 0042 \\
\hline
\end{tabular}

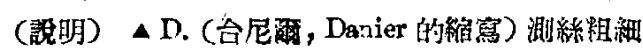
的诂位。

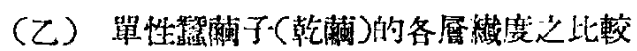
表:

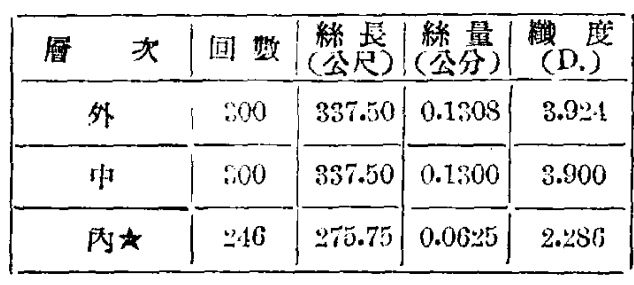

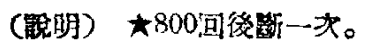

\section{三 莤二代的人工單性糔}

我們把第一代單性㗶育的處女蛾所㡾出的 卵,經續用温水或別種適當的刺激物 (如酷酸、冷 藏、……) 使卵獲得“束激”和“修整”的作用以後,

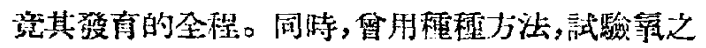
有然, 對于刺激和修整造種動作的影響, 踓已得到 湠汗成果, 但份需要更詳細的分析。在這塞, 且將 養育的經過, 先行唫告。
（甲）第一、二代處女娥的制卵情况，一一茹 根㨜觀察所得，把它記錄下來(宣温維持 $24^{\circ} \mathrm{O}$ )。

\begin{tabular}{|c|c|c|c|c|c|c|c|c|}
\hline 政的日期 & & 代 & 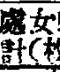 & & 第 & $\bar{F}$ & 4 & 女 \\
\hline （化蛾後） & I & II & III & IV & V & VI & VII & W \\
\hline 第二天 & 78 & 73 & 10 & 128 & 47 & 24 & 14 & 17 \\
\hline 第 三 天 & 105 & 148 & 6. & 177 & 60 & 67 & 63 & 56 \\
\hline 第四天 & 77 & 131 & 150 & 153 & 267 & 81 & 241 & 228 \\
\hline 第 五 天 & 119 & $\left.10^{\circ}\right)$ & 130 & 0 & 210 & 94 & 56 & 78 \\
\hline 第六天 & 148 & 111 & 210 & 0 & 58 & 51 & 31 & 190 \\
\hline 第七天 & 48 & 34 & 97 & 0 & 0 & 38 & 0 & 16 \\
\hline 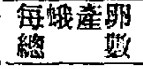 & 578 & & 65 & 68 & 64 & 355 & 405 & 58 \\
\hline
\end{tabular}

（乙）第二代單性發育的卵之扸孪化率及其幼 星生長情况，一一第二代單性發育的率，能够完全 變色的,一般說來, 是佔總数的 $2 / 5$ 。現根㹉 6 月 14日(第0190次) 實駿觀察了 8 隻蛾子所產的卵, 經過適當處理後,其:變色率如下:

\begin{tabular}{|c|c|c|c|c|c|}
\hline \multirow{2}{*}{ 蛾 } & \multirow{2}{*}{ 眀的總教 } & \multicolumn{2}{|c|}{ 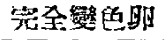 } & \multicolumn{2}{|c|}{ 易部戀色瑚 } \\
\hline & & 邞数 & $\%$ & 忛 敖 & $\%$ \\
\hline 1 & 196 & 121 & 61.2 & 38 & 19.3 \\
\hline 2 & 102 & 46 & 45.0 & 53 & 51.9 \\
\hline 3 & 54 & 29 & 53.7 & 23 & 42.6 \\
\hline 4 & 201 & 126 & 62.1 & 61 & 30.0 \\
\hline 5 & 67 & 56 & 83.5 & 6 & 8.9 \\
\hline 6 & 143 & 108 & 75.5 & 10 & 7.0 \\
\hline 7 & 135 & 87 & 64.3 & 30 & 22.2 \\
\hline 8 & 153 & 103 & 71.2 & 38 & 22.2 \\
\hline 對照組* & 32 & 0 & 0 & 3 & 9.4 \\
\hline
\end{tabular}

*天然栺性生殖的㽗。

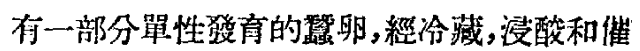
青以後, 在 8 月 29 日開始養有的工作。低照漁酸與 否,分做如下兩組。

第一組, 出冷藏庫後浸酸, 8 月 29 日(淁酸後

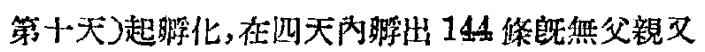

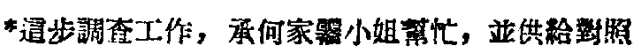
組材料, 謹和謝地。 


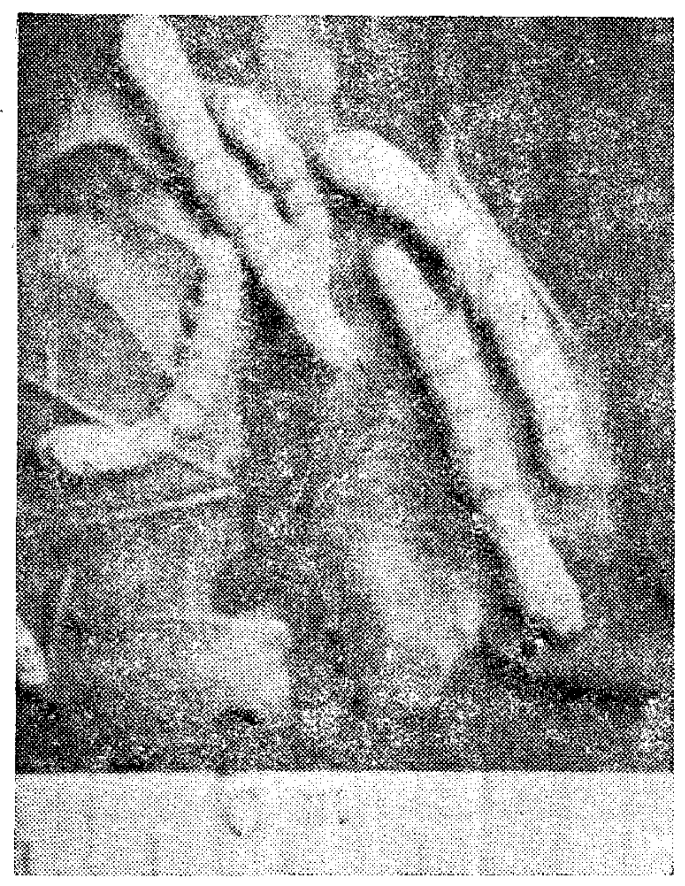

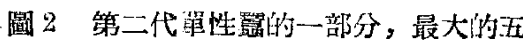

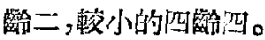

無租父的單性禤, 由于冷藏浸酸等技石影響, 故独 化率僅 $18.9 \%$, 天殈在卵款中的有 $27 \%$ 。

第二組,出冷藏庫後, 不經浸酸的手續, 先讓 它們在宣温的瑾境裹經過數小時, 然後催青, (春

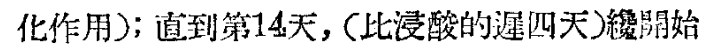

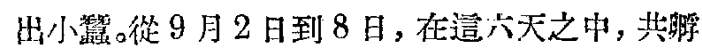

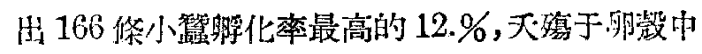
者 $22.4 \%$ 。

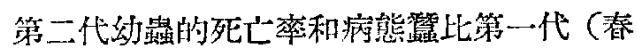

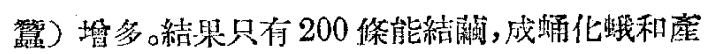
贸, 波有雄性個體。

總結：根握我們幾年連續觀察和實驗的結果 看隶, 家篦人工單性生殖的技術踓已有把握, 結果 亦有可觀; 人工單性的世代, 經過適當的處理以後 能够繼續下去, 而兩性交合可以避免。在理論上,

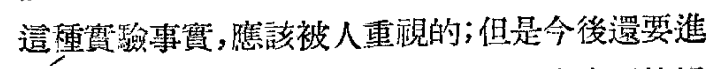
一步,改良技術, 提高其睬化率, 才能有應用的價 值。

\section{約里奧一居里發表韾明 號召舆論质責美國侵略者蕉行細菌戰罪行}

世界和平理事會主筆約里咸一居里於 8 日在巴黎發表警明, 痛厉美國侵略者在朝鮮使用細菌武器

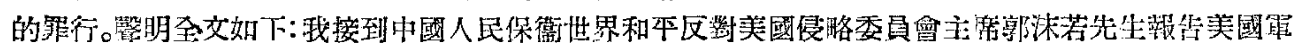
隊在潮鮮使用細䔉武器'的消息的來電, 感到非常震警。

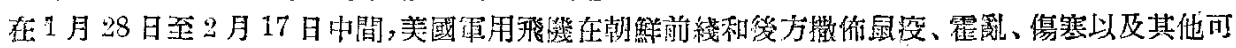

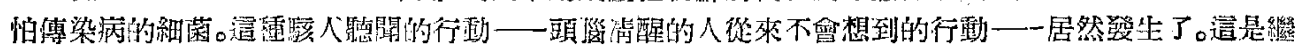

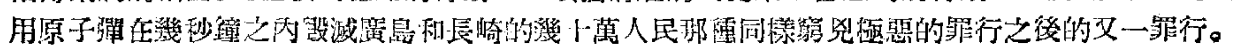

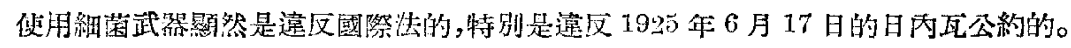

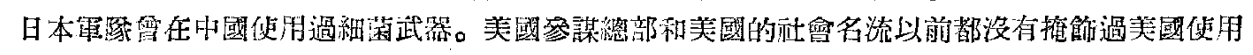
這程武器的淮借工作:和意㵽。

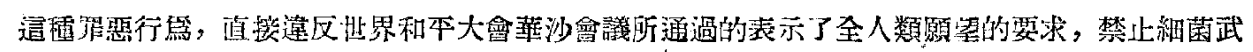
器、化學武器以及其他大量毁減人類的武器的决議。

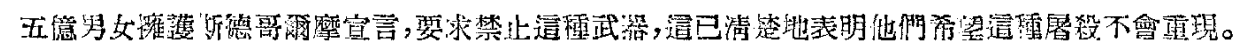

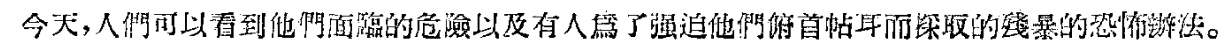

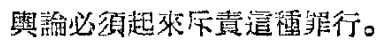

(新華社新聞稿 3 月 10 日)

第四期 科學通報 